\title{
Clinical Observation of Misoprostol before and after Painless Induced Abortion
}

\author{
Yu Cai ${ }^{*}$, Huilian Huang ${ }^{2}$, Jianjun Zhai ${ }^{1}$, Bibo Feng ${ }^{1}$ \\ ${ }^{1}$ Department of Obstetrics and Gynecology, Capital Medical University Affiliated Beijing Tongren Hospital, Beijing, China \\ ${ }^{2}$ Ultrasonography Department, Capital Medical University Affiliated Beijing Tongren Hospital,, Beijing, China \\ Email: *caiyu892002@sina.com
}

How to cite this paper: Cai, Y., Huang, H.L., Zhai, J.J. and Feng, B.B. (2021) Clinical Observation of Misoprostol before and after Painless Induced Abortion. Pharmacology \& Pharmacy, 12, 91-99. https://doi.org/10.4236/pp.2021.125009

Received: March 18, 2021

Accepted: May 28, 2021

Published: May 31, 2021

Copyright $\odot 2021$ by author(s) and Scientific Research Publishing Inc. This work is licensed under the Creative Commons Attribution International License (CC BY 4.0).

http://creativecommons.org/licenses/by/4.0/ (c) (i) Open Access

\begin{abstract}
Background: Though painless abortion is a safe, effective and excellent method of artificial abortion, intravenous anesthesia cannot effectively expand the cervix. Hard and tight cervix often affects the operation and easily induces abortion complications. Misoprostol can induce uterine contraction and soften the cervix. Objective: To investigate the clinical effect of misoprostol on abortion before and after painless induced abortion. Methods: 600 case pregnant women were divided into three groups: A, B and C, 200 case in each group. All patients were anesthetized. In group A, misoprostol 0.2 ug was placed in the posterior fornix of vagina 2 hours before the operation of induced abortion; in group B, misoprostol 0.2 ug was not only placed in the posterior fornix of vagina 2 hours before the operation of induced abortion but also taken orally 2 hours and 6 hours after the operation; in group $\mathrm{C}$, misoprostol was not used before and after the operation. The operation time, intraoperative bleeding volume, postoperative bleeding, the percentage of cervical relaxation and the rate of incomplete abortion among the three groups were compared. Results: Compared with group A and group B, the operation time of group $\mathrm{C}$ was longer and the amount of bleeding was more $(\mathrm{P}<0.05)$, but there was no significant difference between group $\mathrm{A}$ and group $B(P>0.05)$. The duration of bleeding in group $B$ was less than that in group $A(P<0.05)$. The percentage of cervical relaxation in group $A$ and $B$ was higher than that in group $\mathrm{C}(\mathrm{P}<0.05)$. The rate of incomplete abortion in group $\mathrm{B}<$ group $\mathrm{A}<$ group $\mathrm{C}(\mathrm{P}<0.05)$, and there was no residual uterine cavity in group B. Conclusion: The use of misoprostol before and after painless induced abortion can not only shorten the time of operation, reduce intraoperative and postoperative vaginal bleeding, but also has not incurred incomplete abortion(primary outcome).
\end{abstract}

\section{Keywords}

Painless Induced Abortion, Misoprostol, Incomplete Induced Abortion 


\section{Introduction}

Abortion as a remedy for contraceptive failure has been widely used. With the improvement of anesthesia level, more and more early pregnant women choose painless abortion. Painless abortion is a safe, effective and excellent method of artificial abortion, in which propofol and fentanyl are used in combination with intravenous anesthesia. However, hard and tight cervix (especially in the first pregnant women) often affects the operation and easily causes complications, such as induced abortion syndrome, cervical injury, uterine perforation, bleeding, even incomplete abortion, long-term cervical dysfunction and so on, and intravenous anesthesia cannot effectively expand the cervix. At present, in order to reduce the complications of induced abortion, scholars at home and abroad have done a lot of research on the technology of promoting cervical "maturation" (dilation and softening) before the operation of induced abortion [1] [2] [3] [4] [5], but there is no research on the postoperative incomplete human flow or residual uterine cavity. Misoprostol, a prostaglandin E1 drug synthesized in the 1980s, is widely used in drug abortion and induction of mid-term pregnancy [6] [7], which can induce uterine contraction and soften the cervix, effectively promote cervical ripening and strengthen uterine contraction [8] [9] [10]. However, it has been studied that the application of misoprostol before painless induced abortion is beneficial to cervical dilatation in China, but the effect of postoperative application has not been studied both domestic and internation [11]. The purpose of this study is to explore the effect of misoprostol used before and after the painless abortion operation on the complications of painless induced abortion, and to find a safe and effective painless abortion.

\section{Data and Methods}

\subsection{Clinical Data}

Pregnant women who need to terminate pregnancy were selected from the family planning clinic of Beijing Tongren Hospital Affiliated to Capital Medical University from January 2019 to January 2020. All the pregnant women (gestational weeks less than 10 weeks) who voluntarily requested to terminate pregnancy were included in the standard: pregnant women who met the outpatient pregnancy termination index, all the tests were normal without surgical contraindications and no anesthesia contraindications. The informed consent of abortion and anesthesia were signed before operation. Except those with special complications, missed abortion, spontaneous abortion and incomplete abortion. According to the stratified randomization, the patients were divided into three groups: A, B and C. calculate sample size of each group based on research hypothesis is 200 cases respectively. All patients were anesthetized. Group A: misoprostol 0.2 ug was placed in the posterior fornix of vagina 2 hours before the operation of induced abortion; group B: misoprostol $0.2 \mathrm{ug}$ was placed in the posterior fornix of vagina 2 hours before the operation of induced abortion, and misoprostol 0.2 ug was orally taken 2 hours and 6 hours after operation respective- 
ly; group C: misoprostol was not used except for intravenous anesthesia. There was no statistical difference in age, gestational age, first pregnancy and whether there was a history of cesarean section among the 3 groups $(P>0.05)$, which was comparable, see Table 1.

\subsection{Methods}

All pregnant women completed routine hematuria, urine HCG, liver and kidney function, hepatitis B five items, immunity three items, ECG, vaginal secretion examination, ultrasound routine examination, and the anesthesia department consultation before the appointment of surgery. No diet for 6 hours before operation, the position, size and accessories of the uterus of all pregnant women were assess by Intravaginal examination. Establish the vein access of upper limbs, inhale oxygen through nose catheter, after routine disinfection of vulva and vagina, lay sterile hole towel, anesthesiologist give propofol intravenously, gynecologist then uses vaginal speculum exposing cervix and sterilizes vagina and cervix , and a series of operation procedures: Probe the depth of uterine cavity, dilate the cervix ,Suck out uterine cavity contents by negative pressure suction tube 1 - 2 circles, Curette gently and curette the uterine angle and the uterine cavityl circles, At last Suck out uterine cavity 1 circles, Simultaneously explore the depth of the uterine cavity, Take out the vaginal speculum, Check the tissue scraped out of the uterine cavity, and check whether the villi and fetal buds are consistent with the gestational age.

\subsection{Observation Indexes}

1) Operation time, intraoperative bleeding volume and postoperative bleeding duration. 2) The occurrence of cervical relaxation and incomplete induced abortion. The relaxation of the cervix is based on whether it passes the No. 6cervical dilatation stick as standard. According to the patient's anesthesia, cervical relaxation, operation time, amount of bleeding and the results of ultrasound examination at 2 weeks after operation, the operation effect is judged. If there is no residual in the uterine cavity at 2 weeks after operation and bleeding stops, the abortion is successful, otherwise the abortion is incomplete; if there is incomplete

Table 1. Comparison of general data of pregnant women in 3 groups.

\begin{tabular}{cccccc}
\hline Group & $\mathrm{n}$ & Age (year) & $\begin{array}{c}\text { Gestational } \\
\text { week (week) }\end{array}$ & $\begin{array}{c}\text { First pregnancy } \\
(\mathrm{n}, \%)\end{array}$ & $\begin{array}{c}\text { History of cesarean } \\
\text { section }(\mathrm{n}, \%)\end{array}$ \\
\hline A & 200 & $29.85 \pm 5.63$ & $7.8 \pm 2.1$ & $113(56.50)$ & $63(31.50)$ \\
B & 200 & $29.89 \pm 5.37$ & $8.1 \pm 2.2$ & $115(57.50)$ & $65(32.50)$ \\
C & 200 & $29.65 \pm 5.71$ & $7.9 \pm 2.0$ & $108(54.00)$ & $60(30.0)$ \\
$F\left(\chi^{2}\right)$ & & 1.501 & 1.912 & 0.608 & 0.309 \\
$P$ & & 0.107 & 0.010 & 0.750 & 0.830 \\
\hline
\end{tabular}


abortion, according to the size of the residual tissue, drug abortion or uterine cleaning can be added to remedy; if there is no follow-up, it will be removed.

\subsection{Statistical Analysis}

SPSS20.0 software was used for statistical analysis. The measurement data was expressed in $(\bar{x} \pm s)$. The mean of multiple groups was compared by ANOVA, and snk-q method was used for comparison between the two groups. The comparison of the count data was made by $\chi^{2}$ test, with $\mathrm{P}<0.05$ as the difference.

\section{Results}

\subsection{Comparison of Operation Time, Bleeding Volume and Postoperative Bleeding Time in Three Groups}

2 case and 3 cases were removed due to no follow-up visit, respectively in group $\mathrm{B}$ and group $\mathrm{C}$. the operation time of group C (7.24 \pm 2.53 minutes), compared with group A (3.53 \pm 2.31 minutes) and group B (3.60 \pm 1.96 minutes), was longer. the intraoperative blood loss of group $\mathrm{C}(29.07 \pm 9.07 \mathrm{ml})$ was respectively more than that of group A $(18.53 \pm 8.42 \mathrm{ml})$ and group B $(17.53 \pm 9.47$ $\mathrm{ml})$, the difference was statistically significant $(\mathrm{P}<0.05)$, but there was no statistically significant difference between group $A$ and group $B$ in operation time and intraoperative bleeding volume $(\mathrm{P}>0.05)$. Postoperative bleeding time of group B (3.35 \pm 2.41 day) was significantly shorter than that of group A $(5.65 \pm 3.62$ day) and group $C(9.63 \pm 5.34$ day), The difference was statistically significant $(\mathrm{P}<0.05)$, see Table 2.

\subsection{Comparison of Cervical Relaxation and Incomplete Abortion in Three Groups}

The proportion of cervical relaxation in group A $(169 / 200,84.50 \%)$ and group B $(168 / 198,84.85 \%)$ was higher than that in group C $(60 / 197,30.61 \%)$, the difference was statistically significant $(\mathrm{P}<0.05)$. Comparison of the incidence of incomplete abortion in three groups, the difference was statistically significant $(\mathrm{P}<0.05)$, respectively, group A $(11 / 200,5 \%)$, group, $\mathrm{B}(0 / 198,0 \%)$ and group C $(20 / 197,10.2 \%)$, and above all group B had no residual tissues in uterine cavity, see Table 3.

Table 2. Comparison of operation time, bleeding volume and postoperative bleeding time in three groups.

\begin{tabular}{ccccc}
\hline Group & $\mathrm{N}$ & $\begin{array}{c}\text { Operation } \\
\text { time }(\mathrm{min})\end{array}$ & $\begin{array}{c}\text { Bleeding } \\
\text { volume }(\mathrm{ml})\end{array}$ & $\begin{array}{c}\text { Postoperative bleeding } \\
\text { time }(\mathrm{d})\end{array}$ \\
\hline $\mathrm{A}$ & 200 & $3.53 \pm 2.31$ & $18.53 \pm 8.42$ & $5.65 \pm 3.62$ \\
$\mathrm{~B}$ & 198 & $3.60 \pm 1.96$ & $17.53 \pm 9.47$ & $3.35 \pm 2.41$ \\
$\mathrm{C}$ & 197 & $7.24 \pm 2.53^{\star *}$ & $29.07 \pm 9.07^{\star *}$ & $9.63 \pm 5.34^{\star \star}$ \\
$\mathrm{F}$ & & 86.765 & 49.226 & 58.792 \\
$P$ & & $<0.001$ & $<0.001$ & $<0.001$ \\
\hline
\end{tabular}

Note: group C compared with group $\mathrm{A},{ }^{\star} \mathrm{P}<0.05$; compared with group $\mathrm{B},{ }^{*} \mathrm{P}<0.05$. 
Table 3. Comparison of cervical relaxation and incomplete abortion in 3 groups.

\begin{tabular}{cccc}
\hline Group & $\mathrm{n}$ & Cervical relaxation $\mathrm{n}(\%)$ & Incomplete abortion $\mathrm{n}(\%)$ \\
\hline $\mathrm{A}$ & 200 & $169(84.50)$ & $11(5.00)$ \\
$\mathrm{B}$ & 198 & $168(84.85)$ & $0^{*}$ \\
$\mathrm{C}$ & 197 & $60(30.61)^{* \#}$ & $20(10.20)^{*}$ \\
$\chi^{2}$ & & 87.318 & 10.692 \\
$P$ & & 0.001 & 0.004 \\
\hline
\end{tabular}

Note: group C compared with group $\mathrm{A},{ }^{\star} \mathrm{P}<0.05$; compared with group $\mathrm{B},{ }^{*} \mathrm{P}<0.05$.

\section{Discussion}

The traditional method of dilation of artificial abortion on the traction of the cervix can stretch the cervix and stimulate the uterine wall, which can cause discomfort and pain during the operation and affect physical and mental health of the patient. In recent years, due to the application of intravenous anesthesia, painless artificial abortion has the advantages of rapid analgesia, good effect, high efficiency, safety, reliability, and fewer side effects and so on. It has solved the physical pain and psychological fear of patients, and has become an effective, safe and acceptable surgical method in artificial termination of pregnancy. However, although the smooth muscle of uterus can relax after intravenous anesthesia, it cannot effectively dilate the cervix. If we want to achieve effective dilation of the cervix, the amount of anesthetic will be increased to relaxed uterine, which will affect the uterine contraction during and after operation, and prone to excessive curettage to stop bleeding, and increase the complications of operation, especially, the uterus perforation, bleeding and Intrauterine adhesions and so on [3] [4] [5]. Misoprostol, a synthetic prostaglandin E1 derivative, which can promote the release of a variety of proteins, promote the degradation of collagen fibers and activate prostaglandin receptor and make the uterus excited and cervical softened [6] [7] [8] [9] [10]. It not only has a good effect of uterine contraction, cervical ripening and cervical dilation, but also reduce the various complications risk of abortion. In the past few years have seen a hot-button topic of drug abortions (mifepristone and misoprostol) in medical world. The majorities of women choose this way to terminate pregnancy (7 weeks of gestation). However, it is not suitable for all early pregnancy. and it can cause vaginal bleeding for a long time and easily induce infection and incomplete abortion [12] [13] [14] [15]. There are some studies [16] [17] [18]. That treatment of incomplete abortion with misoprostol provided by midwives is equally effective, safe and accepted by women as when administered by physicians in a low-resource setting. On this basis, we put forward an idea that small amount of misoprostol combined with painless abortion in order to reduce each other's shortcomings, to reduce the complications of abortion, to reduce the pain of patients.

The result showed that there was no significant difference between group A and group $B$ in operation time and bleeding volume $(P>0.05)$, but the operation 
time and bleeding volume of group $\mathrm{C}$ were longer or more than that of group $\mathrm{A}$ and group $\mathrm{B}(\mathrm{P}<0.05)$. This may be attributable to misoprostol that can make the cervix mature, soften and expand [8] [9] [10] [19] [20]. however, the full expansion of the cervix leads to the expansion of the cervix with or without the expansion rod, which shortens the operation time and reduces the operation time of the uterine cavity. In addition, the contraction of the uterine body is conducive to hemostasis. This is why the operation time of group A and B is shorter than that of group C. Meanwhile, this reduces the incidence of intrauterine adhesions and better protects the endometrium, and decrease amount of anesthesia. Compared with simple painless induced abortion, the combined use of misoprostol before painless induced abortion has less bleeding, shorter operation time, shorter anesthesia time and less dosage of narcotic drugs. Therefore, the amount of bleeding of painless induced abortion before operation with misoprostol is significantly less than that of simple painless induced abortion. The postoperatively bleeding time of group B was shorter than that of group A. This is because misoprostol can make the postoperative uterus excited and play the role of vasoconstriction and hemostasis.

The results also showed that there was no significant difference in the proportion of cervical flaccidity between Group A and Group B ( $P>0.05)$, but the proportion of cervical flaccidity in group $\mathrm{C}$ was significantly lower than that of group A and group $B(P<0.05)$, suggesting that misoprostol can significantly soften and dilate the cervix [8] [9] [10] [11]. In addition, the incidence of incomplete abortion in three groups, the difference was statistically significant $(\mathrm{P}<$ $0.05)$, respectively, group B (0\%), group A (5\%), group C (10.2\%), and above all group $B$ had no residual tissues in uterine cavity, This may be due to the addition of misoprostol after operation in group B, which can make the uterus contract and discharge a small amount of residual intrauterine tissue, so as to prevent anesthesia from affecting the uterine contraction, affecting the residual tissue and eliminating blood clots. In addition, the amount of medicine taken after operation is small, only $0.2 \mu \mathrm{g}$ each time, resulting in less severe uterine contraction, so most patients have no obvious abdominal pain [21] [22] [23] [24].

\section{Conclusion}

In conclusion, ordinary painless abortion, which is difficult to dilate the uterine opening, has a long operation time and a lot of bleeding, resulting in a high rate of incomplete abortion; the painless abortion with misoprostol 0.2 ug placed in the posterior vault of vagina 2 hours before operation is easy to dilate the cervix, to short operation time and to less bleeding, but there is still the incidence of incomplete abortions; however, misoprostol used before and after painless induced abortion is not only easy to dilate the cervix, but also to shorten the operation and to reduce the occurrence of vaginal bleeding and incomplete abortion, which also avoids the doctor-patient dispute caused by incomplete abortion, and avoids the psychological burden and physical injury caused to the patients by 
recleaning the palace, and reduces the dosage of anesthetic. This way is conducive to the rapid recovery of the patients after operation, improving the operation quality and safety, and has better social and economic benefits. This study will test the hypothesis that the use of misoprostol before and after painless induced abortion was better than that of painless induced abortion alone and that of Misoprostol only before operation in terms of reducing the complications of abortion and minimizing the pain of patients, especially, to shorten the time of operation, to reduce intraoperative and postoperative vaginal bleeding, to be painless, the most important of all, to abate none about the incidence of incomplete abortion (primary outcome) and so on. However, this experiment is only an observational study, the sample size is small, the specific results still need a large of samples for experimental studies to confirm. In addition, during the outbreak of the novel coronavirus, in order to cut down hospital admissions, decrease the number of patients coming back to the hospital and reduce patient aggregation and cross-infection, in this way, the patient's menstrual flow after operation for one month at home would only detect early urine pregnancy. If they would be checked urine early pregnancy negative, the patient does not need to come back to the hospital, which greatly reduces the number of patients coming back to the hospital and minimizes the risk of cross-infection.

\section{Acknowledgements}

Our clinical observational study would not have been possible without the help of all the doctors who helped to collect the original data, along with permission from the participants for ongoing research. The authors would like to express the deepest appreciation to participants who participated in this study by providing their valuable information. The authors would like to thank the staffs of the Department of Obstetrics and Gynecology, Beijing Tongren Hospital, Capital Medical University Beijing. Without their persistent help, this study would not have been possible.

\section{Conflicts of Interest}

The authors declare no conflicts of interest regarding the publication of this paper.

\section{Statement}

The study found that the use of misoprostol before and after painless induced abortion can not only shorten the time of operation, reduce intraoperative and postoperative vaginal bleeding, but also has not incur incomplete abortion(primary outcome). A large of sample study will be expected to do in the future.

\section{References}

[1] Whitehouse, K., Fontanilla, T., Kim, L., Tschann, M., Soon, R., Salcedo, J., et al. (2018) Use of Medications to Decrease Bleeding during Surgical Abortion: A Survey 
of Abortion Providers' Practices in the United States. Contraception, 97, 500-503. https://doi.org/10.1016/j.contraception.2018.02.015

[2] Singh, R.H., Montoya, M., Espey, E. and Leeman, L. (2017) Nitrous Oxide versus Oral Sedation for Pain Management of First Trimester Surgical Abortion-A Randomized Study. Contraception, 96, 118-123. https://doi.org/10.1016/j.contraception.2017.06.003

[3] Zane, S., Creanga, A.A. and Cynthia, J. (2015) Abortion-Related Mortality in the United States 1998-2010. Obstetrics \& Gynecology, 126, 258-265. https://doi.org/10.1097/AOG.0000000000000945

[4] Soulat, C. and Gelly, M. (2006) Immediate Complications of Surgical Abortion. Journal de Gynécologie Obstétrique et Biologie de la Reproduction, 35, 157-162. https://doi.org/10.1016/S0368-2315(06)76389-X

[5] Sun, L., Yu, Y. and Qi, X. (2017) Short-Term Effects of Catheter Pressure and Time Control in Vacuum Aspiration Abortion for Early High-Risk Pregnancies. Iranian Journal of Public Health, 46, 634-639.

[6] Fan, G.S., Jin, L., Xi, S. and Li, H. (2005) Clinical Observation of Propofol Combined with Misoprostol for Painless Induced Abortion. National Medical Journal of China, 85, 1106-1108.

[7] Hoffer, M.C., Charlier, C., Giacalone, P.L., et al. (1998) Evaluation of Combination RU 486-Laminaria Tents-Misoprostol-Peridural Anesthesia in Second and Third Trimester Induced Abortions. Journal of Gynecology Obstetrics and Human Reproduction, 27, 83-86.

[8] Osoti, A., Kiprop Kibii, D., Kual Tong, T.M. and Maranga, I. (2018) Effect of Extra-Amniotic Foley's Catheter and Vaginal Misoprostol versus Vaginal Misoprostol alone on Cervical Ripening and Induction of Labor in Kenya: A Randomized Controlled Trial. BMC Pregnancy Childbirth, 18, Article No. 300. https://doi.org/10.1186/s12884-018-1793-2

[9] Timmons, B.C., Reese, J., Socrate, S., Ehinger, N., Paria, B.C., Milne, G.L., et al. (2014) Prostaglandins Are Essential for Cervical Ripening in LPS-Mediated Preterm Birth But Not Term or Antiprogestin-Driven Preterm Ripening. Endocrinology, 155, 287-298. https://doi.org/10.1210/en.2013-1304

[10] Zhang, Y., Zhu, H.-P., Fan, J.-X., Yu, H., Sun, L.-Z., Chen, Li., et al. (2015) Intravaginal Misoprostol for Cervical Ripening and Labor Induction in Nulliparous Women: A Double-blinded, Prospective Randomized Controlled Study. Chinese Medical Journal, 128, 2736-2742. https://doi.org/10.4103/0366-6999.167299

[11] Zhou, Y., Xun, H.H. and He, Y.J. (2014) Clinical Study of Misoprostol Combined with Atropine in Painless Induced Abortion. Medical Recapitulate, 20, 3415-3417.

[12] Agaoglu, A.R., Aslan, S., Emre, B., Korkmaz, Ö., Özdemir Salci, E.S., Kocamuftuoglu, M., et al. (2014) Clinical Evaluation of Different Applications of Misoprostol and Aglepristone for Induction of Abortion in Bitches. Theriogenology, 81, 947-951. https://doi.org/10.1016/j.theriogenology.2014.01.017

[13] Schreiber, C.A., Creinin, M.D. and Atrio, J. (2018) Mifepristone Pretreatment for the Medical Management of Early Pregnancy Loss. New England Journal of Medicine, 378, 2161-2170. https://doi.org/10.1056/NEJMoa1715726

[14] Gatter, M., Cleland, K. and Deborah, L. (2015) Efficacy and Safety of Medical Abortion Using Mifepristone and Buccal Misoprostol through 63 Days. Contraception, 91, 269-273. https://doi.org/10.1016/j.contraception.2015.01.005

[15] Kim, C., Barnard, S., Neilson, J.P., Hickey, M., Vazquez, J.C. and Dou, L. (2017) Medical Treatments for Incomplete Miscarriage. Cochrane Database of Systematic 
Reviews, 1 Article No. CD007223. https://doi.org/10.1002/14651858.CD007223.pub4

[16] Ibiyemi, K.F., Ijaiya, M.A. and Kikelomo, T. (2019) Randomised Trial of Oral Misoprostol versus Manual Vacuum Aspiration for the Treatment of Incomplete Abortion at a Nigerian Tertiary Hospital. Sultan Qaboos University Medical Journal, 19, e38-e43. https://doi.org/10.18295/squmj.2019.19.01.008

[17] Makenzius, M., Oguttu, M., Klingberg-Allvin, M., Gemzell-Danielsson, K., Odero, T.M.A. and Faxelid, E. (2017) Post-Abortion Care with Misoprostol-Equally Effective, Safe and Accepted When Administered by Midwives Compared to Physicians: A Randomised Controlled Equivalence Trial in a Low-Resource Setting in Kenya. BMJ Open, 7, e016157. https://doi.org/10.1136/bmjopen-2017-016157

[18] Bello, F.A., Fawole, B., Oluborode, B., Awowole, I., Irinyenikan, T., Awonuga, D., et al. (2018) Trends in Misoprostol Use and Abortion Complications: A Cross-Sectional Study from Nine Referral Hospitals in Nigeria. PLOS ONE, 13, e0209415. https://doi.org/10.1371/journal.pone.0209415

[19] Liao, B. and Xiao, X. (2004) Clinical Observation of Propofol and Misoprostol in Induced Abortion. Journal of Jinan University. Natural Science and Medicine, 25, 190-193.

[20] Dao, B., Blum, J., Thieba, B., Raghavan, S., Raghavan, S., Ouedraego, M., Lankoande, J., et al. (2007) Is Misoprostol a Safe, Effective and Acceptable Alternative to Manual Vacuum Aspiration for Postabortion Care? Results from a Randomised Trial in Burkina Faso, West Africa. BJOG, 114, 1368-1375. https://doi.org/10.1111/j.1471-0528.2007.01468.x

[21] Chen, B.A., Reeves, M.F., Mitchell, D., Gilles, J.M., Barnhart, K., Westhoff, C., et al. (2008) Misoprostol for Treatment of Early Pregnancy Failure in Women with Prior Uterine Surgery. American Journal of Obstetrics \& Gynecology, 198, 626.e1-626.e5. https://doi.org/10.1016/j.ajog.2007.11.045

[22] Løkeland, M., Bjørge, T., Iversen, O.-E., Akerkar, R. and Bjørge, L. (2017) Implementing Medical Abortion with Mifepristone and Misoprostol in Norway 1998-2013. International Journal of Epidemiology, 46, 643-651. https://doi.org/10.1093/ije/dyw270

[23] Song, L.P., Tang, S.Y., Li, C.L., Zhou, L.-J. and Mo, X.-T. (2018) Early Medical Abortion with Self-Administered Low-Dose Mifepristone in Combination with Misoprostol. Journal of Obstetrics and Gynaecology Research, 44, 1705-1711. https://doi.org/10.1111/jog.13716

[24] Li, C., Chen, D., Song, L., Wang, Y., Zhang, Z.-F., Liu, M.-X. and Chen, W.-L. (2015) Effectiveness and Safety of Lower Doses of Mifepristone Combined with Misoprostol for the Termination of Ultra-Early Pregnancy: A Dose-Ranging Randomized Controlled Trial. Reproductive Sciences, 22, 706-711. 